\title{
NUEVOS BODEGONES NAPOLITANOS EN ESPAÑA
}

La influencia de la escuela italiana en el desarrollo de la pintura española del bodegón barroco es aceptada por todos, y en concreto la aportación de la escuela napolitana, sin lugar a dudas una de las más destacadas en esta especialidad. Los elementos de unión entre ambas escuelas respecto a la naturaleza muerta durante el s. XVII han sido ya ampliamente estudiados, si bien todavía hay ciertos aspectos por investigar como es la relación entre ellas durante los últimos años del siglo. Recordemos como en los años noventa, gracias a la presencia de Luca Giordano en la Corte madrileña, el dominio de la pintura napolitana en Madrid fue casi total ${ }^{1}$. La estancia de este pintor en España provocó que llegasen numerosas obras y artistas que marcarán claramente la actividad artística de estos años. Entre ellos se encontrarán diversos pintores de género de los cuales se desconoce casi por completo su estancia en nuestro país y especialmente su producción pictórica. En este artículo publicamos una serie de obras, hasta ahora inéditas, existentes en las ricas colecciones de Patrimonio Nacional, que pertenecen a algunos de estos artistas como son Abraham Brueghel, Andrea Belvedere y los hijos de Giuseppe Recco, Elena y Nicola María. El dar a conocer estas obras ayudará al estudio de estos pintores napolitanos así como a entender un poco mejor la situación finisecular del género tanto en Italia como en España.

Comenzaremos el estudio con el artista de origen flamenco Abraham Brueghel ${ }^{2}$ (Amberes, 1631 - Nápoles, 1697), eslabón final de una de las dinastías más importantes para el desarrollo del género desde sus comienzos. Formado con su padre Jan Brueghel «el joven» (Amberes, 1601-1678) en su ciudad natal, se puede decir que su desarrollo y madurez artística se producen en Italia, entre Roma y Nápoles. Este pintor será puente entre ambas ciudades al llevar a la Ciudad Partenopea las innovaciones del barroco pleno que se producen en este género en la Ciudad Eterna. El conocimiento de su obra es fundamental para comprender la evolución de la pintura de género del último tercio del siglo y sobre todo la de comienzos del s. XVIII.

Hasta ahora era desconocida la presencia de obras de este artista en las colecciones antiguas españolas. Afortunadamente, podemos publicar dos de gran importancia pues pertenecen al Patrimonio Nacional, lo que nos hace pensar que permanecen en las colecciones reales desde antiguo. Se trata de la pareja de cuadros: Jardín con flores y frutas, aves y una fuente (Fig. 1 , óleo sobre lienzo, $75,5 \times 85, \mathrm{n}^{\circ}$ inv. 10010181) y Fuente con flores y frutas en un jardín con muchacha (Fig. 2, óleo sobre lienzo, 75, $5 \times 100$, fdo.: «ABreghel. F./ 1686», $\mathrm{n}^{\circ}$ inv. 10010184). Ambas se encuentran en el Palacio de El Pardo, en la zona dedicada a residencia. Se desconoce por completo el origen de estas obras, que carecen de número de inventario y que no parecen coincidir con ninguna de las numerosas obras que aparecen en los inventarios reales atribuidas a los Brueghel ${ }^{3}$. Podemos pensar que tal vez fuesen adquiridas en cualquier

\footnotetext{
${ }^{1}$ Al respecto ver Pintura Napolitana. De Caravaggio a Giordano, cat. exp. Museo del Prado, Madrid, 1985.

${ }^{2}$ Sobre la obra y vida de Abraham Brueghel ver Zeri, F., La Natura Mota in Italia, T. II, Milán, 1989, p. 788 y ss. Es la más completa revisión sobre su obra y estilo, además de aportar toda la bibliografía dedicada al artista. Una aportación más moderna supone el catálogo de la exposición de Munich Natura morta Italiana tra Cinquecento e Settecento, cat. exp. Kunsthalle der Hypo-Kulturstiftung, Munich 2002-2003, Milán, 2002, p. 464. El primero en señalar la presencia de posibles obras suyas en España fue Pérez Sánchez, A. E., «Sobre bodegones italianos, napolitanos especialmente», Archivo Español de Arte, Madrid, 1967, T. XL, p. 317. Lámina V.

${ }^{3}$ No es el lugar para indicar la rica colección de obras que de Pieter y Jan Brueghel se conservan tanto en el Museo del Prado como en Patrimonio Nacional, provenientes todas ellas de las colecciones reales. Sí es curiosa la presencia de obras de Jan Brueghel «el joven», padre de Abraham, en el Museo del Prado, ( $\left.\mathrm{n}^{\circ} 1400,1402,1408\right)$, todas ellas provienen de las colecciones reales de los Austrias, si bien la última fue adquirida en el s. Xvili por Isabel de Farnesio (Díaz Padrón, M., Museo del Prado. Catálogo de Pinturas. Escuela Flamenca siglo xvIl, Vol. I, 1975, pp. 71-73).
} 


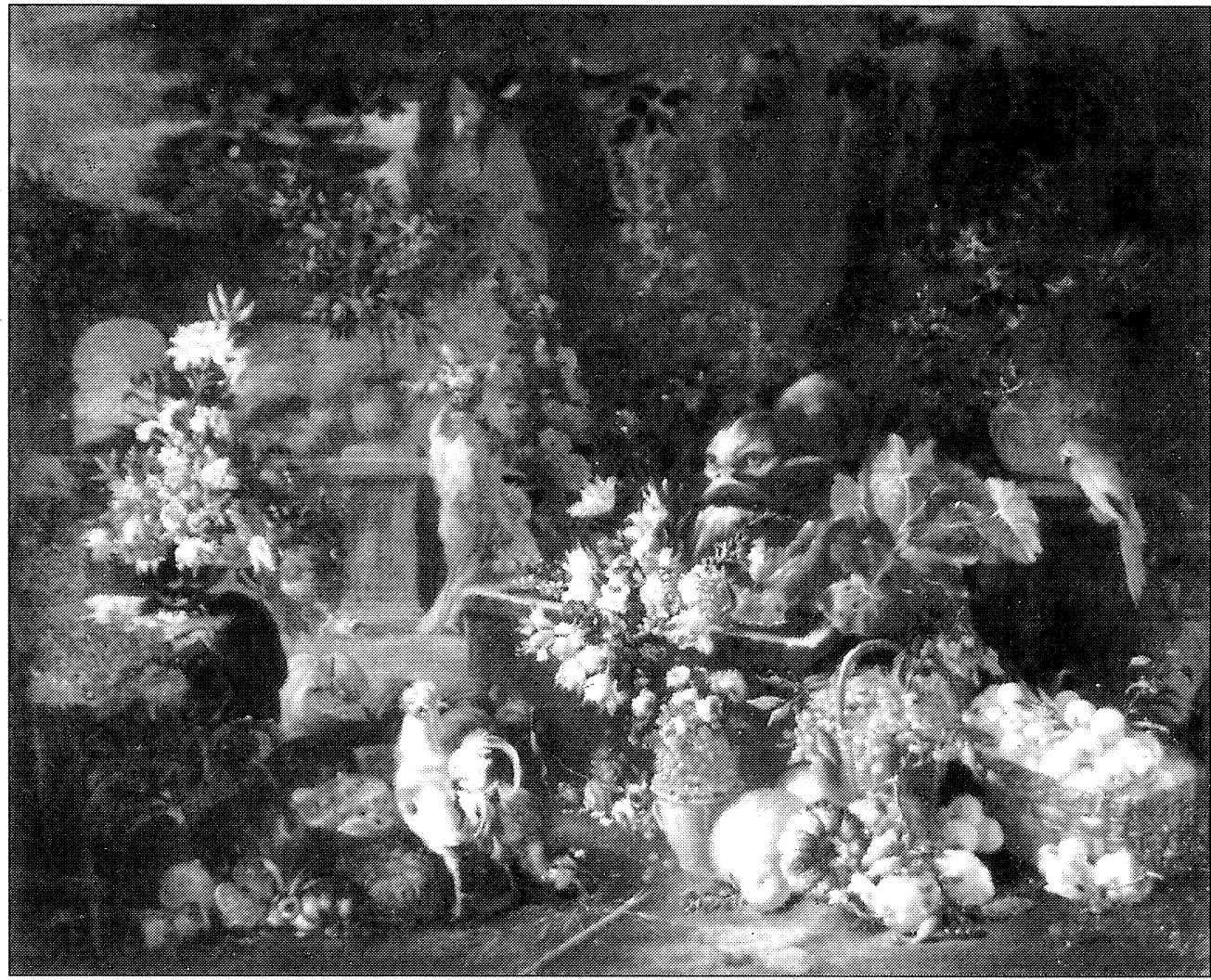

Fig. 1. A. Brueghel: Jardín con flores y frutas, aves y una fuente. Palacio de El Pardo (Madrid).

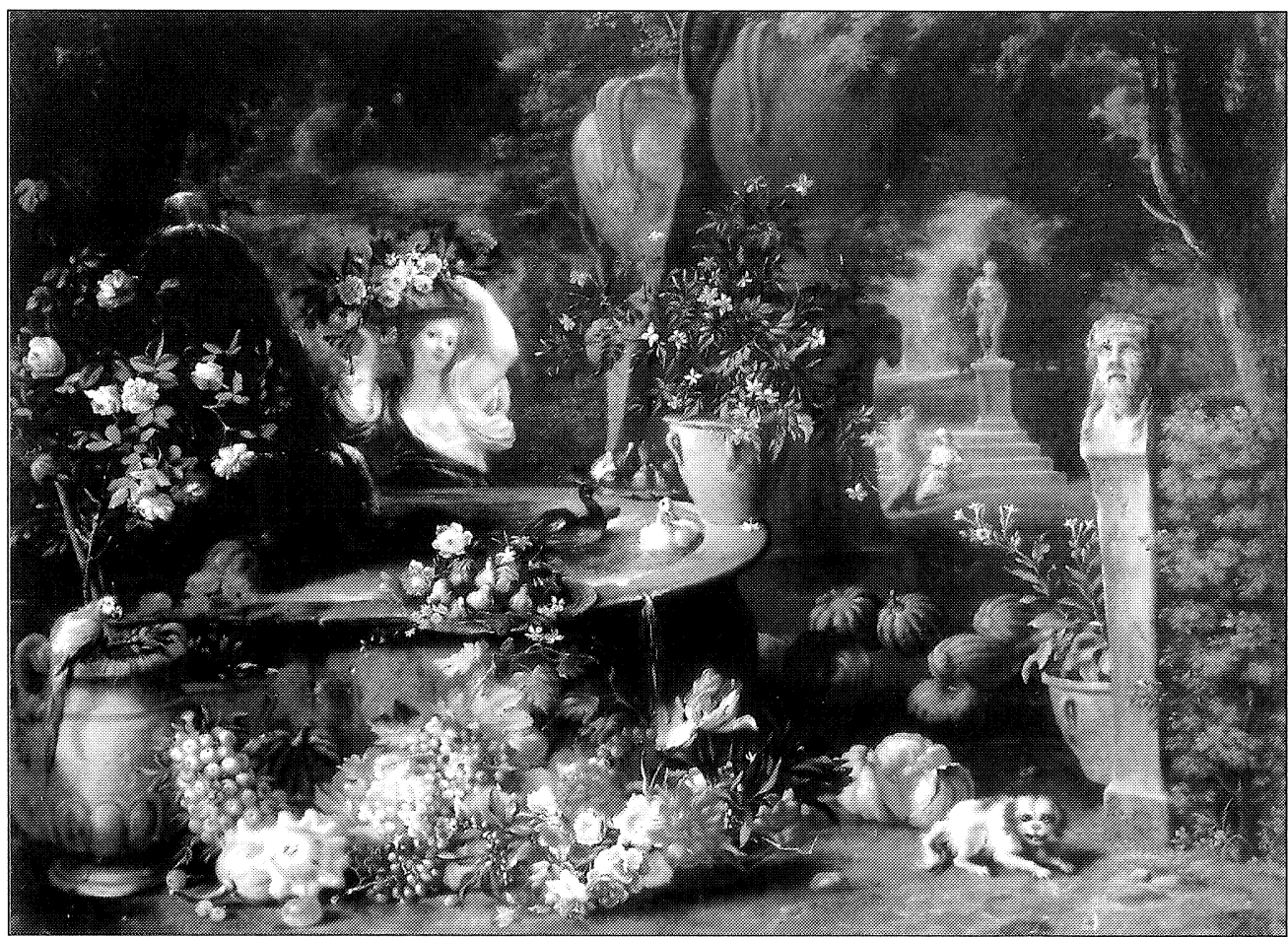

Fig. 2. A. Brueghel: Fuente con flores y frutas en un jardín con muchacha. Palacio de El Pardo (Madrid).

AEA, LXXVIII, 2005, 311, pp. 297 a 331 
momento por los monarcas españoles, aunque no debemos olvidar que la presencia de Giordano en España pudo favorecer la llegada de estas pinturas ${ }^{4}$.

Son obras de su etapa de madurez, cuando el artista ya se ha asentado y trabaja desde hace años en Nápoles (a donde llega en 1675). A pesar de su escaso tamaño, ambas son composiciones complejas y de una cierta monumentalidad. Representan un jardín donde en primer término, a modo de exposición, se distribuyen todo tipo de flores y frutas. Recordemos como De Dominici señalaba la extravagancia del artista a la hora de componer, pues dejaba caer una sandía y la pintaba tal y como quedaba, rodeándola de más objetos ${ }^{5}$. Estos cuadros responden en cierto modo a esta manera de componer, con la sandía rota en uno de ellos y en el otro una calabaza. En torno a ellas se despliegan toda una serie de objetos. Todo ello junto a fuentes que amplían la composición y logran una mayor sensación escenográfica. Se observa una influencia claramente flamenca tomada de su padre y de Frans Snyders, con escenas de bodegón en amplios jardines o paisajes. Esto crea una representación con un resultado final fuertemente decorativo. Es este aspecto, tan denostado por Rafaello Causa ${ }^{6}$, muy evidente en estas obras. Sin duda será este tipo de aparatosas composiciones las que tengan mayor éxito e influyan con mayor fuerza no sólo en los bodegonistas napolitanos de su época como Giovanni Battista Ruopolo (1629-1693) y Giuseppe Recco (1634-1695) sino también en las jóvenes generaciones, representadas por Andrea Belvedere (1652-1732), Aniello Ascione (activo 1680-1708) o Gaetano Cusati (activo hasta 1720). Ya en el s. XviII, su influencia está claramente presente en Gasparo López, «Gasparino» (Nápoles?-Florencia, Venecia 1732/40) y en su más fiel discípulo, Giacomo Nani (1698-1754) ?

Del mismo modo es frecuente en el flamenco la inclusión de aves y perrillos, animales que repite constantemente. Frente al mundo austero y sencillo de la tradición napolitana, este artista une el mundo flamenco con el carácter monumental romano, apuntando en sus obras el gusto por lo gracioso y sofisticado que anuncia el rococó.

En ambas obras aparecen representadas figuras humanas, seguramente realizadas por otra mano. Sabemos que con Brueghel colaboraron pintores de figuras, especialmente en sus años romanos, tales como Gugliemo Cortese y especialmente Carlo Marata ${ }^{8}$. Sin embargo, estarían realizadas en Nápoles por lo que sería difícil una colaboración con pintores de Roma. Además, aunque ambos modelos de mujeres se aproximan mucho a los modelos del pintor clásico, carecen de la monumentalidad de sus obras romanas ${ }^{9}$. Recordemos como Giordano, e incluso

\footnotetext{
${ }^{4}$ No debemos olvidar la relación de Carlos II con el banquero Gaspare Roomer, marchante de arte que proporcionó numerosas obras al rey. Este flamenco gozaba de una importante relación con Abraham Brueghel por lo que pudo ser él quien participase en la venida a España de estas obras (Ruotolo, R., «Mercanti- Collezionisti fiaminghi a Napoli. Gaspare Roomer e i Vandeneyden», Ricerche sul '600 napoletano, Nápoles, 1982, p. 5 y ss.).

${ }_{5}^{5}$ De Dominici, B., Vitte de Pittori, Scultori ed Architetti Napoletani, vol. III, Nápoles, 1742 (edic. facsímil de 1979), p. 298.

${ }^{6}$ Causa, R., «La Natura Morta a Napoli nel sei e nel Settecento», Storia di Napoli, Nápoles, vol. V, 1972, p. 1018. Se puede considerar, a pesar de estar superado en algunos aspectos documentales y de autorías, como el estudio clásico sobre la naturaleza muerta en Nápoles.

${ }^{7}$ Sobre la evolución de la pintura de género a fines del s. xviI consultar la obra ya citada de Causa (1972). Hay nuevos datos documentales y sobre todo numerosas reproducciones de sus obras, en Spinosa, N., «La Natura Morta a Napoli», $L a$ Natura Morta In Italia, T. II, Milán, 1989, p. 852-871.

${ }^{8}$ Ya De Dominici aportó noticias sobre estas colaboraciones que se convirtieron en algo común tanto en Roma como en Nápoles. Está especialmente estudiada la colaboración con Gugliemo Cortese (Graf; Schleier, «Gugliemo Cortese und Abraham Brueghel», Panteón, enero-marzo, año XXXI, 1973, pp. 46-57).

${ }^{9}$ Especialmente la muchacha con flores (Fuente con flores y frutas en un jardín con muchacha) que nos mira de frente guarda una extraordinaria semejanza con el lienzo conservado en el Museo del Prado Una joven con un canasto de flores (óleo sobre lienzo, $132 \times 98, \mathrm{n}^{\circ}$ cat. 5267). Podríamos apuntar a una colaboración entre ambos autores en la que Brueghel realizaría las flores. En el otro lienzo, Jardín con flores y frutas, aves y una fuente, la figura en el fondo y de espaldas demuestra un conocimiento por parte del artista del arte romano, pues no es sino una copia de la muchacha que porta un cántaro de agua en el fresco del Incendio del Borgo, pintado por Rafael en las Stanze Vaticane.
} 
Solimena, también estaban acostumbrados a este tipo de colaboraciones, si bien no parecen obras de su mano.

Finalmente destaca la incorporación de elementos de la Antigüedad, en este caso la Herma o los relieves clásicos, objetos que asimilará en su etapa romana y que llevará a la Ciudad Partenopea donde serán asimilados por Andrea Belvedere.

Es el Abate Andrea Belvedere (Nápoles, 1652-1732) ${ }^{10}$ el autor de la siguiente obra que publicamos. Se trata de un pintor que tendrá una mayor importancia para el mundo español por lo que esta nueva obra adquiere un cierto relieve. Su relación con Abraham Brueghel es admitida por todos los historiadores y sobre todo por sus contemporáneos como De Dominicci que, para compararlos, utiliza la respuesta que Luca Giordano dio a Carlos II cuando el monarca solicitaba información sobre un buen pintor de flores para traerlo a la Corte. Así le dice «che in tal genere non avea veduto pittore uguale, per la soma naturaleza che dava a suoi Fiori, Frutta, Volatili, Vasi d'Árgento, e altre simili co e: che benchè vi fusse un Fiammingo nominato Abram Brughel, famoso per la gran fantasia del porre insieme, ed in tal parte superiore all Ábate, ad ogni modo egli lo superaba nello studio, e nella esatezza delle cose che dipingea, e massimamente ne fiori» ${ }^{11}$. Estas palabras debieron ser suficientes para convencer al monarca de la conveniencia de hacer venir al napolitano, que llegará a España hacia 1794-1795 ${ }^{12}$.

Es muy poco lo que se sabe de su estancia en la Corte pues carecemos por ahora de datos documentales y debemos contentarnos con las obras que dejó en España. Estas son escasas si tenemos en cuenta que estuvo en nuestro país cerca de seis años. La más completa, y por ahora única, aproximación a su producción española es la realizada por Pérez Sánchez en su tesis doctoral donde dio a conocer cuatro cuadros de su mano además de fuentes documentales sobre otros tantos ${ }^{13}$. Gracias a De Dominici sabemos como realizó «per quel magnánimo Principe vari quadri che furono graditi da lui, e da tutte le corte». Pero no sólo pintó para el rey, también lo hizo para diversos nobles ${ }^{14}$. En 1700 debido, según parece, a una discusión con Luca Giordano, vuelve a Nápoles, donde abandonará casi por completo la pintura de flores y se dedicará al teatro y a la escenografía.

Afortunadamente hoy podemos aumentar el catálogo de obras realizadas por el Abate Belvedere durante su estancia española. Se trata del óleo Flores en un paisaje (Fig. 3, óleo sobre lienzo, $76 \times 64$ ), obra que pertenece al Patrimonio Nacional (hasta ahora atribuida a escuela española, $\mathrm{n}^{\circ}$ Inv. 10072063) y que se encuentra actualmente en el Palacio de El Pardo, en el Salón de Piano. En el cuadro aparece representado un jarrón de barro con diversas flores (rosas, claveles, etc...); al lado, una rama de azahar y capuchinas penden de un tronco y caen sobre un arroyo. Flores, hojas y cántaro perlados de gotas de agua tan del gusto napolitano; al

${ }^{10}$ Sobre la vida y la obra de este magnífico pintor de flores sigue siendo fundamental la obra de De Dominici ( $O p$. cit., p. 570-573). Dentro de la historiografía moderna es ya un clásico el estudio de Rafaelo Causa, Andrea Belvedere, Nápoles, 1963, que supuso la primera y única biografía dedicada al pintor. Más moderno aunque sin una renovada visión del artista es el capitulo, escrito por Middione, que se dedica al artista dentro de la obra La Natura Morta in Italia, Milano, 1989 , p. 936-940, importante por las numerosas reproducciones de su obra y por aportar numerosa bibliografía.

${ }^{11}$ De Dominici, op. cit., p. 572.

${ }^{12}$ Middione, R. (1989), op. cit., p. 936, apunta que tal vez fuese llamado a la Corte española por la repentina muerte de Giuseppe Recco, también traído por Giordano, a su llegada a España.

${ }_{13}$ Pérez Sánchez, A. E., Pintura Italiana del s. XVII en España, Madrid, 1965, p. 378-380. En ese momento sólo dio a conocer cuatro obras, los dos jarrones del Museo del Prado ( $\mathrm{n}^{\circ} 459$ y 550), el cuadro en colaboración con Solimena del Museo de San Telmo de S. Sebastián (Dep. Museo del Prado, $\mathrm{n}^{\circ}$ 551) y un jarrón de la Col. Pérez Ortiz de Madrid. Además documentó los cuadros que se encontraban en las colecciones reales.

${ }^{14}$ De Dominici, Op. cit., p. 572: «Dipinse ancora per alcuni de'Signori di quella Corte quadri di Frutta, e Fiori, e fece degli Ucelli assai terminati, $i$ qualli eran molto graditi, e con special gusto osservatti, e desiderati». Muestra de esta labor es el óleo que se conserva en Madrid en la Col. del Duque del Infantado, Bodegón con frutas y flores en un paisaje, publicado en Jordan, W.; Cherry, P., El bodegón español de Velázquez a Goya, cat. Exposición en la National Gallery de Londres, Madrid, 1995, p. 148, fig. 119.

AEA, LXXVIII, 2005, 311, pp. 297 a 331 
fondo aparece un paisaje montañoso de clara influencia giordanesca. Como elemento anecdótico aparecen posadas sobre las flores unas mariposas e incluso un pequeño caracol sobre las hojas.

En el ángulo inferior izquierdo, inscrito en rojo, aparece el número 973 que sin duda corresponde al del Inventario del Palacio Real de Madrid de 1772: «Cuarto del Infante Don Xavier. 972, 973, dos floreros con unos tarros de barros de vara de caída, y más de tres quartas de ancho; originales del Abate Bervedel». Ambos procedían del Palacio del Buen Retiro ${ }^{15}$. El compañero se haya en el Museo del Prado, Jarrón de Flores y pájaros (óleo sobre lienzo, $77 \times 65$, $\mathrm{n}^{\circ}$ cat.: 569 ) ${ }^{16}$, en cuyo ángulo inferior se puede ver el número 972 correspondiente al inventario anteriormente citado.

Las obras son de extremada calidad y demuestran como el artista es, sin duda, una de los pintores de género más

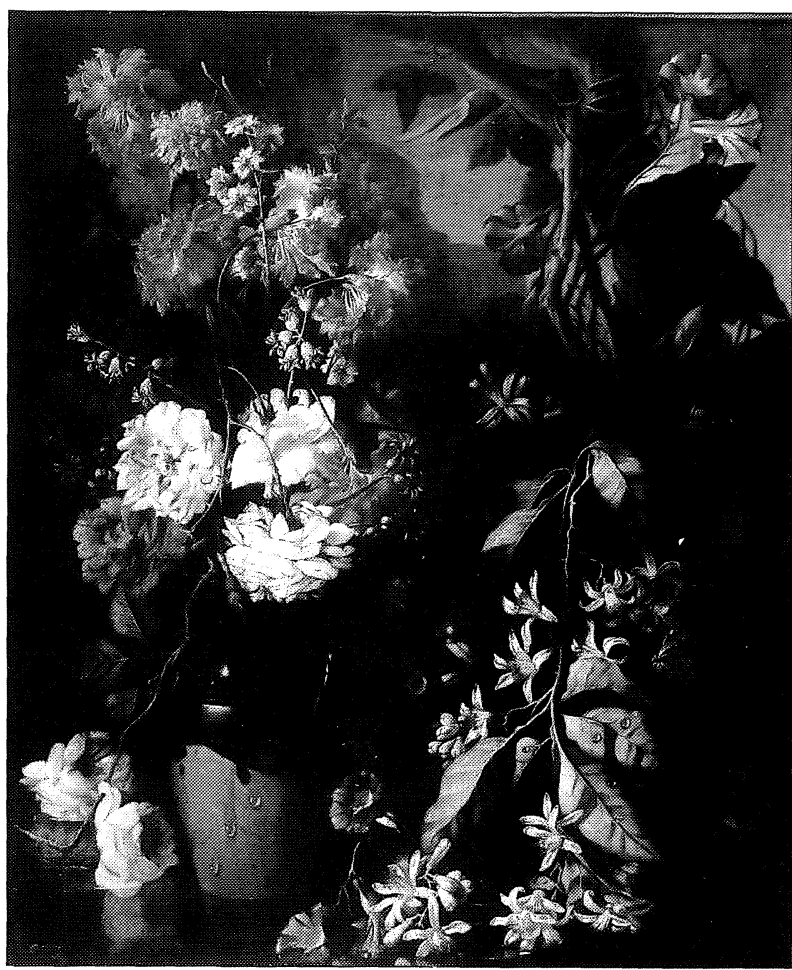

Fig. 3. A. Belvedere: Flores en un paisaje. Palacio de El Pardo (Madrid) destacados de Europa. Al contemplar y comparar ambas obras se descubre como hacían pandán: el modelo del jarrón de barro vidriado se repite, pero se coloca a la derecha en la del Prado y en la izquierda en la de Patrimonio. También las respectivas composiciones se orientan en direcciones opuestas.

La composición floral del cuadro del Museo del Prado muestra una relación más directa con los floreros del mismo autor que también se conservan allí (Cat. ${ }^{\circ} 459,550$ ) y que manifiestan una deuda con respecto a los modelos de Karol Vogelaert y Frans Werner Tamm. Lo mismo sucede en el jarrón de flores de la que ahora publicamos, muy parecido al de su compañera del Prado. Sin embargo, en la rama de azahar con capuchinas que cuelgan de un tronco y que caen sobre el agua donde reflejan su imagen, repite casi de una forma igual el tipo de composición de una de las obras más emblemáticas del autor. Nos referimos a las Bolas de Nieve y Capuchinas del Museo Nazionale di Capodimonte ${ }^{17}$. El efecto de luz es muy parecido, consiguiendo un fuerte efectismo sin abandonar el naturalismo tan ligado a la tradición napolitana y que le convirtió, como señalaba Causa, en la opción napolitana frente al fácil decorativismo de Abraham Brueghel ${ }^{18}$. Este uso de la luz se aprecia muy bien en el paisaje del fondo, que tiene una semejanza notable con las obras de su periodo napolitano, especialmente con la anteriormente citada, así como con algunas del Museo Correale de Sorrento ${ }^{19}$.

\footnotetext{
${ }^{15}$ AGP, Sección Administrativa, Leg. 38.

${ }^{16}$ Esta obra ya fue recogida por Pérez Sánchez (1965, p. 483) en su tesis doctoral atribuyéndola al ámbito de Paolo Pórpora, sin dejar de señalar su relación con Belvedere. Es en 1985 (Pintura Napolitana. De Caravaggio a Giordano, Cat. exp., Museo del Prado, Madrid, 1985, p. 84-85, $\mathrm{n}^{\circ}$ 11) cuando se atribuye definitivamente a Belvedere.

${ }_{17} 99 \times 74$, óleo sobre tabla, $\mathrm{n}^{\circ}$ inv. Q 252. Recordemos como para Causa esta obra suponía el cénit de la producción del artista pues en ella lograba el pintor un lirismo pictórico total (op. cit., 1963).

${ }^{18}$ Causa, op. cit., 1963.

${ }^{19}$ Especialmente con Fiori, uva e papagayo, Inv. 2992, $128 \times 102$.
} 
La obra, sin duda, está realizada durante su etapa española (1694-1700), si bien su interés por el naturalismo y la composición en cierto modo austera, lo sitúa lejos de las fastuosas y complicadas obras del Museo Correale de Sorrento o del Pitti de Florencia ${ }^{20}$. Este naturalismo hace pensar que fuera realizada durante los primeros años de su estancia en la que pudo conocer la obra de Juan Arellano.

La posible relación de este artista con otros pintores de flores españoles durante su periodo en nuestro país no se puede establecer, si bien no es arriesgado suponer que el madrileño Francisco Pérez Sierra (1627-1709) no debió de ser ajeno a la obra realizada por este artista, como sucede con otros pintores del cambio de siglo que aún están por estudiar ${ }^{21}$.

La última obra que se encuentra en Patrimonio Nacional y que aquí publicamos, es un bodegón de una artista casi desconocida artística y documentalmente. Se trata de Elena Recco (fines del s. XVII, principios del s. XvIII) ${ }^{22}$, hija del gran Giuseppe Recco. Según De Dominici, quien la califica de «brava pitricce», estuvo en España, si bien no existe documento alguno que lo demuestre. Siempre siguiendo al biógrafo napolitano, sabemos como el mismo Carlos II, posiblemente aconsejado por Luca Giordano, la mandó venir a España y fue conducida a nuestro país por la Condesa de Santiesteban, esposa del virrey de Nápoles, que volvió a la península en 1695. Según parece la artista obtuvo en nuestro país todo tipo de honores si bien desconocemos en que consistirían éstos ${ }^{23}$.

$\mathrm{Su}$ obra es prácticamente desconocida, y siempre aparece ligada a la pintura de género, especialmente a la de peces, lo que demuestra un aprendizaje con su padre, destacado pintor de este subgénero de la naturaleza muerta ${ }^{24}$.

Hasta ahora se desconocían obras suyas en España. Afortunadamente, ahora podemos mostrar que en la riquísima colección del Patrimonio Nacional se encuentra un cuadro de esta pintora. Se trata de Flores y Frutas (Fig. 4, fdo.: «D Elena Recco», óleo sobre lienzo, $45 \times 69$, Inv. $\mathrm{n}^{\circ}$ 10055546), obra que se encuentra en el complejo de la Zarzuela. El cuadro representa un recipiente de cristal con frutos y a la izquierda un jarrón de flores, algunas de ellas por detrás. En el ángulo inferior izquierdo aparece el $\mathrm{n}^{\circ} 481$ que corresponde al del Inventario Real de 1794: «Otra de Elena Recco, con un florero, de una vara de largo y media de alto, marco antiguo... 80 reales» ${ }^{25}$.

Es el primer cuadro de flores y frutas que se conoce de la pintora. La obra es, sin lugar a dudas, deudora de las enseñanzas de su padre aunque no llega a la excelsa perfección de este a la hora de representar el natural. A pesar de ello, demuestra una notable calidad que la convierte en una especialista del género en el cambio de siglo que debe ser valorada. Así, en la obra se descubre cómo toma de su padre el tipo de composición sencilla, con los objetos sobre una mesa de piedra, y cómo muestra un interés por un estudio lumínico naturalista que

${ }^{20}$ La Natura Morta a palazzo e in villa. Le collezioni dei Medici e dei Lorena, cat. exp. Galleria Palatina di Palazzo Pitti, Florencia, 1998, pp. 60-61, nº 18.

${ }^{21}$ Sobre la pintura de flores madrileña de fin de siglo xvir, Cherry, P., Arte y Naturaleza. El Bodegón Español de Siglo de Oro, Madrid, 1999, pp. 287-322.

${ }^{22}$ Según parece es la misma Madalena que aparece citada en numerosos inventarios napolitanos, Labrot, G., Italian Inventories 1. Collections of paintings in Naples. 1600-1780, Munich, 1992, p. 309 y ss.

${ }^{23}$ De Dominici, op. cit., p. 297. Curiosamente no vino con su padre, quien llega a España en 1794, desembarcando en Alicante donde muere a los pocos meses. Venía acompañado de dos de sus hijos, Tomasso, sacerdote, y Antonio, que volvieron a Nápoles tras la falta de su padre.

${ }^{24}$ Sobre Elena Recco, la revisión más completa sobre su obra así como bibliografía puede encontrarse en La Natura Morta, op. cit., 1989, t. II, p. 912.

${ }^{25}$ Inventarios Reales. Carlos III. 1789-1790. T. I, Madrid, 1987, p. 293. El dato documental ya fue señalado por Pérez Sánchez, (Pintura Barroca Italiana en España, 1965, p. 431-432), única obra que recoge la información de su estancia en la Corte madrileña. En ella señalaba la existencia de otros tres cuadros más, que también se encontraban en las colecciones reales, de dimensiones muy parecidas y con la misma temática.

AEA, LXXVIII, 2005, 311, pp. 297 a 331 


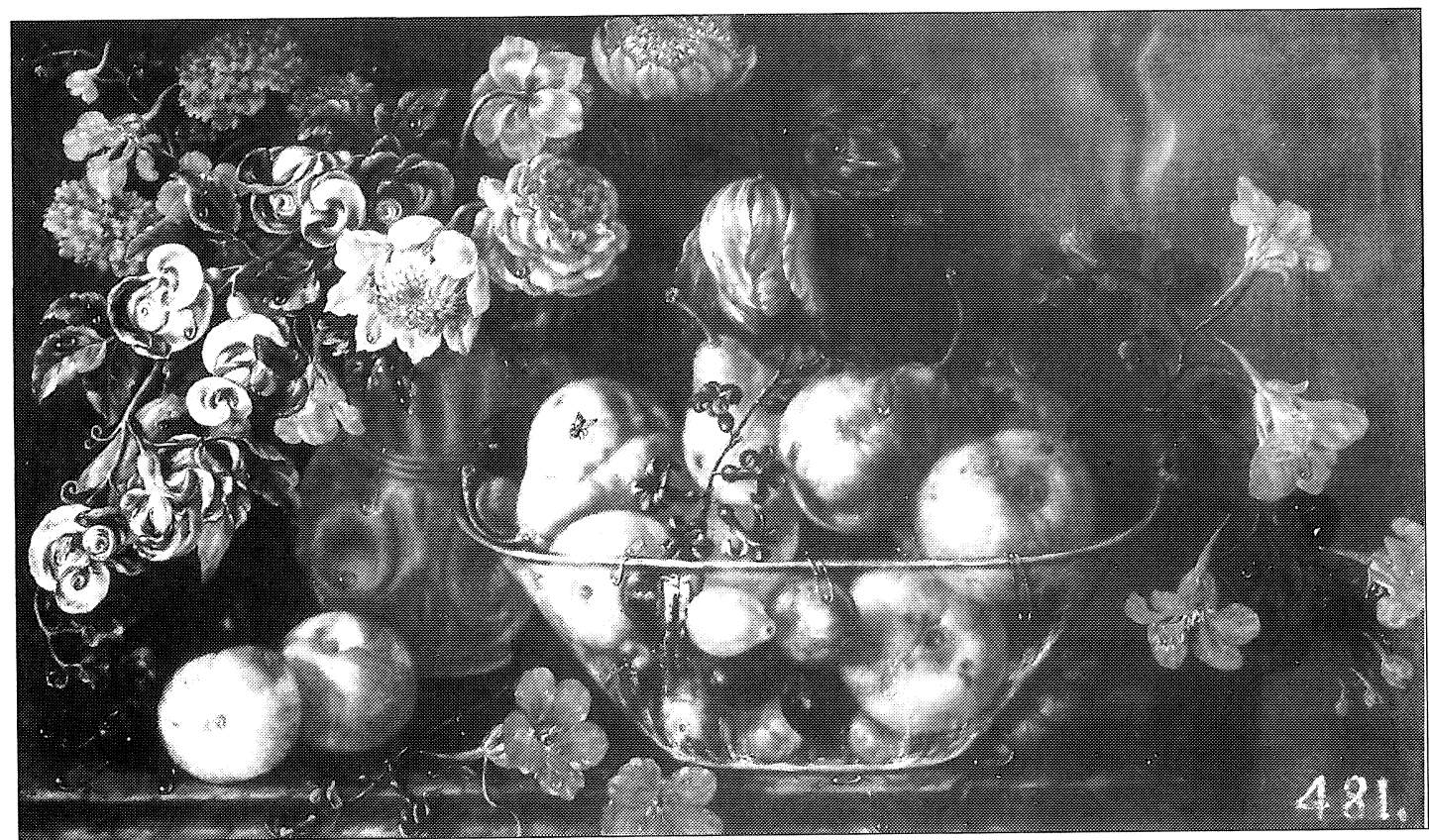

Fig. 4. E. Recco: Flores y frutas. Complejo de La Moncloa. Madrid.

adolece de un cierto arcaísmo si pensamos que la obra se realiza a fines del s. XVII, cuando el género ya ha tomado un nuevo camino más colorista y efectista en composición y luz. El modo de hacer las frutas está claramente relacionado con las que realiza su padre, como sucede con las flores, aunque con una factura un tanto más seca y una falta de vitalidad en la técnica ${ }^{26}$.

Es muy interesante la presencia del búcaro, pieza cerámica típicamente española ${ }^{27}$ pero que la artista sin duda conocía por las obras de su padre ${ }^{28}$. Tras la publicación de esta obra se le podrán atribuir a esta artista otras que hasta ahora se relacionaban con su padre o con la escuela napolitana. No sabemos el tiempo que permaneció en España, posiblemente volviese a Nápoles tras la muerte del rey en 1700 .

Por último, y a pesar de no pertenecer al Patrimonio Nacional, aprovechamos para dar a conocer otra obra inédita relacionada con la familia Recco. Se trata de un Bodegón de peces (Fig. 5, firmado «N. MRecco») ${ }^{29}$, que hace poco tiempo apareció en el mercado anticuario madrileño y es la primera vez que se publica. Sin duda la firma corresponde a Nicolo María Recco, que se supone hermano de Elena e hijo de Giuseppe. Recordemos que Giuseppe tuvo

\footnotetext{
${ }^{26}$ Giuseppe Recco es especialmente conocido (gracias a Bernardo De Dominici) como pintor de peces pero en los últimos años y gracias a la publicación de diversas obras se ha demostrado como era un excelente pintor de flores y fruta de lo cual son buena muestra las inmensas composiciones del Museo Nazionale de Capodimonte (sobre estos cuadros véase $I$ tesori dei d'Ávalos, catálogo de la exposición en Nápoles, Nápoles, 1995, p. 168-9, 172-173, nº 87, 89).

${ }^{27}$ Sobre la presencia del búcaro en la pintura de bodegones véase Seseña, N., «El rango de la cerámica en el Bodegón», en El Bodegón, Galaxia Gütemberg, Madrid, 2000.

${ }^{28}$ En el Museo Narodowe de Varsovia se encuentra un bodegón de Giuseppe Recco, Natura morta con colección de cristales (Natura Morta italiana, tra Cinquecento e Settecento, cat. exp. Kunsthalle der Hypo-Kulturstiftung, Munich 2002 2003, Milán, 2002, pp. 212-213) en el que aparecen representados varios tipos de búcaros. Las flores aquí representadas son una muestra más de las deudas de Elena con su padre. Un ejemplo más cercano lo encontramos en la Colección de la Casa Ducal de Medinacelli en Sevilla, se trata del Bodegón con un criado negro, en el que Giuseppe realiza una magnífica muestra de barros rojos (Pintura Napolitana. De Caravaggio a Giordano, cat. Exp. Madrid, Museo del Prado, 1985, pp. 256-257., $\left.\mathrm{n}^{\circ} 106\right)$.
}

${ }^{29}$ Óleo sobre lienzo, $127 \times 121$. 


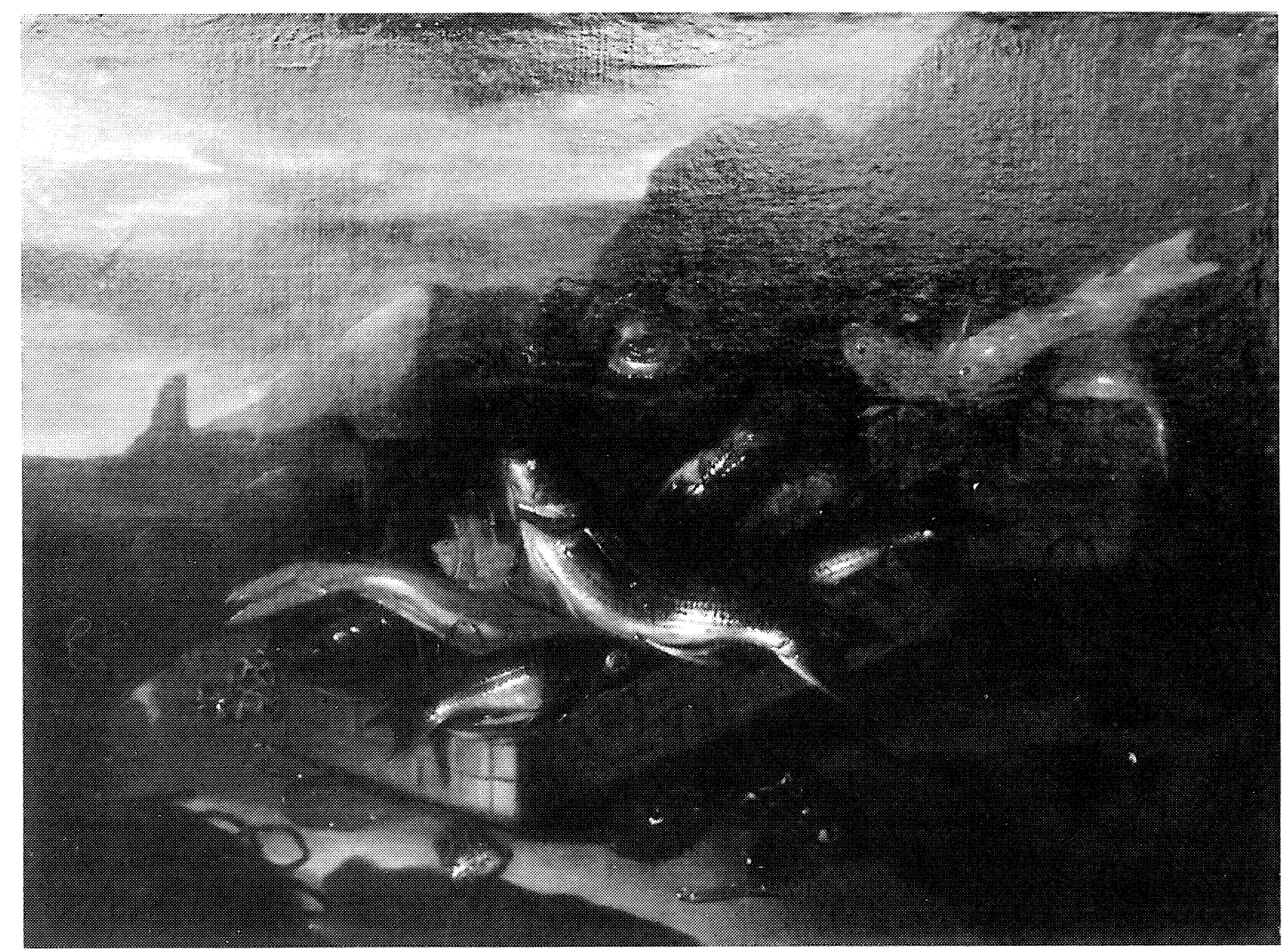

Fig. 5. N. M. Recco: Bodegón de peces. Madrid, colección particular.

al menos doce hijos, de los cuales sabemos que dos se dedicaron a la pintura ${ }^{30}$ : Elena, estudiada más arriba y el poco a poco más estudiado Nicolo María Recco (activo a finales del s. XVII y principios del s. XVIII) que al igual que su padre y hermana se dedicó a la pintura de peces $^{31}$. Se desconoce si este artista estuvo en España, aunque podemos suponer al carecer de noticias suyas que no viniese nunca.

La obra está dentro de la estela de los dos Bodegones de peces, que se encuentran en una colección particular madrileña, dados a conocer por Pérez Sánchez ${ }^{32}$. Al igual que sucedía con Elena, en la obra de Nicolo María se nota el aprendizaje con su padre, si bien se aprecia una composición más sencilla y una factura un tanto más seca y torpe. La obra no aporta ninguna novedad, convirtiéndose el hijo en un fiel imitador de lo creado por el padre. A pesar de ello es una obra de calidad en la que consigue representar fielmente los efectos brillantes de las escamas de los peces. La obra es un claro ejemplo del declive en el que entrará la pintura napo-

\footnotetext{
${ }^{30}$ No se puede asegurar con certeza que Gaetano Recco fuese hijo de Giuseppe, lo cierto es que sí era algún familiar cercano. Se trata de un personaje realmente enigmático, tanto en su vida como en su obra. Sorprendentemente en 1700 se encontraba en Madrid tasando las pinturas de don Pedro Bonilla Malo, ayuda de furrier de las reales Caballerizas de la Reina (Agulló Cobo, M., Más Noticias sobre pintores madrileños de los ss. XVI al xVIII, Madrid, 1981, vid. Vocem). No vino con Giuseppe Recco por lo que es posible que lo hiciese con Elena Recco. Sobre su presencia en España y las obras aquí realizadas véase Pérez Sánchez, A. E., «Algunos pintores rezagados en el Madrid de Felipe V», Archivo Español de Arte, $\mathrm{n}^{\circ} 231,1985$, pp. $210-212$.

${ }^{31}$ Sobre Nicola María Recco véase La Natura Morta in Italia, 1989, T. II, p. 913. Algunas precisiones sobre ambos hermanos en relación con su padre las encontramos en De Vito, «Un giallo per Giuseppe Recco ed alcune postille per la natura morta napoletana del '600», Ricerche sul'600 napoletano, Nápoles, 1988, p. 67.

${ }^{32}$ Pérez Sánchez, A. E., «Sobre bodegones italianos, napolitanos especialmente», Archivo Español de Arte, 1967, T. XL, p. 319. Lámina IV.
}

AEA, LXXVIII, 2005, 311, pp. 297 a 331 
litana de género en la segunda década del s. XVIII. El paso siguiente será la obra de Giacomo Nani, activo a partir de los años veinte y que no es sino el último paso hacia la decadencia de un género que en Nápoles alcanzó una de las más altas cotas.

Es difícil, tal y como se encuentra el estado actual del estudio del bodegón español en el cambio de siglo, determinar la influencia que estos artistas tuvieron en el mundo español. Lo que no debemos olvidar es que estos especialistas no debieron pasar inadvertidos para los pintores españoles y que su manera de pintar tuvo que influir, de una manera notable, en ellos.

ANDRÉS SÁNCHEZ LÓPEZ Universidad Complutense de Madrid 